\title{
Elite Disability Sport Coaches' Views on Sport Psychology
}

\author{
Tânia Bastos ${ }^{1,2}$, Rui Corredeira ${ }^{3}$, Michel Probst ${ }^{4} \&$ António M. Fonseca ${ }^{1}$ \\ ${ }^{1}$ Centre of Research, Education, Innovation and Intervention in Sport (CIFI2D), Faculty of Sport, University of \\ Porto, Porto, Portugal \\ ${ }^{2}$ Maia Institute of Higher Education, Research Centre in Sport and Physical Activity (CIDAF), Maia, Portugal \\ ${ }^{3}$ Research Centre in Physical Activity, Health and Leisure (CIAFEL), Faculty of Sport, University of Porto, \\ Porto, Portugal \\ ${ }^{4}$ Faculty of Kinesiology and Rehabilitation Sciences, Research Group for Adapted Physical Activity and \\ Psychomotor Rehabilitation, Catholic University of Leuven, Belgium \\ Correspondence: Tânia Bastos, Faculdade de Desporto da Universidade do Porto, Rua Dr. Plácido Costa, 91 - \\ 4200.450 Porto, Portugal. Tel: 351-220-425-200. E-mail: tbastos@fade.up.pt
}

Received: December 2, 2013

doi:10.5539/ijps.v6n1p33
Accepted: December 27, 2013 Online Published: January 23, 2014

URL: http://dx.doi.org/10.5539/ijps.v6n1p33

\begin{abstract}
Although the coach is a key element in the psychological preparation of the athletes, few is known about what coaches from disability sport context think about the importance of psychological preparation. Therefore, this study aimed to explore: 1) the educational background of disability sport coaches, 2) the perceptions of the coaches on the importance of psychological preparation for their athletes, and 3) the opinions of the coaches regarding the role of sport psychologists. Semi-structured interviews were conducted with Portuguese elite disability sport coaches $(n=10$; male $=8$ and female $=2$; swimming $=4$, track and field $=2$, boccia $=3$ and rowing $=1$ ) included in the Paralympic Project London 2012. Standard qualitative methodology and content analysis were used to analyse the data. The participants revealed an educational background in sport sciences and in sport psychology. A high status of sport psychology and psychological preparation also emerged from the data. Full receptiveness to work with sport psychologists was exhibited, although some participants mentioned barriers to sport psychologists' intervention (e.g., coach awareness, athlete receptiveness, time, finances). In general, the findings of this study highlighted the importance of sport psychology in Portuguese disability sport.
\end{abstract}

Keywords: educational background, psychological preparation, sport psychologists, qualitative methodology

\section{Introduction}

The main goal of psychological skills training (PST) programs is to help athletes to consistently perform closer to their maximal potential in practice and in a competition setting (Burton \& Raedake, 2008). However, the success of PST programs is dependent on the coach's actions and attitudes towards it. The coach is the manager of the team and has great influence in the lives of their athletes. Moreover, coaches have the power to decide if agents outside the team staff, such as sport psychologists, can interfere with their team and athletes (Morris, 1997). Consequently, a positive or negative attitude of the coach towards sport psychologists will influence the degree of adherence in PST programs showed by athletes.

Although most of the coaches recognize the importance of psychological preparation and view the training of psychological skills as one of the tools to help athletes to reach maximal performance (Gould, Flett, \& Bean, 2009; Leffingwell, Durand-Bush, Wurzberger \& Cada, 2005; S. B. Martin, 2005), some coaches can be unwilling to try specific psychological techniques or express negative viewpoints towards using a sport psychologist. Accordingly, Weinberg and Gould (2011) systematized a variety of barriers that can limit a coach's commitment to psychological training. For instance, coaches can erroneously believe that PST programs take too much time of the training session. The time pressure is another barrier identified by coaches to justify the lack of psychological intervention in the practice setting (Gould, Medbery, Damarjian, \& Lauer, 1999). According to Voight and Callagham (2001) the lack of finance is also identified as one of the major restrictions for collaborative work between the coach and the sport psychologist. Another erroneous assumption is that psychological support is only needed when deep-rooted psychological problems occur in psychologically "weak" athletes. The stigma that links the sport psychologist to a "shrink" is one of the major barriers that sport 
psychologists have to face (Partington \& Orlick, 1987; Ravizza, 1988). Finally, some coaches believe that PST is a miraculous recipe for a quick improvement in performance. This misconception related with unrealistic expectations can be identified in two situations. Coaches expect that a short intervention just before major competitions will produce psychological benefits among athletes. In the same way, coaches expect that psychological training will help athletes to perform above their physical, technical and tactical skills and minimal efforts are needed to reach amazing performances. Although psychological factors play an important role in influencing competitive outcomes, PST programs require long, consistent and systematic practice to help athletes perform at or near their maximal sport capabilities (Burton \& Raedake, 2008).

The previously mentioned barriers can be explained by the lack of knowledge about what sport psychology is and how it can be used. Therefore, it is necessary to invest in the educational background of coaches to open views about the benefits of psychological intervention and the positive contribution experts make in the field of sport psychology (Gould et al., 1999).

According to Burton and Raedake (2008), one of the roles of coaches is to train athletes to be able to develop specific psychological skills. Coaches must believe in the value of psychological training, understand their principles and apply them on regular basis in the coaching plan. Additionally, coaches should be able to identify those athletes that reveal specific psychological needs that can only be fulfilled with the assistance of sport psychologists. In order to achieve this understanding, Caruso (2004) suggested that coaches should learn the basic science of sport psychology. This could be an important step to overcome the lack of scientific and technical intervention and, simultaneously, avoid trial-and-error learning as stated by Gould et al. (2009). In this regard, several studies have been conducted to examine the coaches' level of knowledge on sport psychology (Gould et al., 1999; Sullivan \& Hodge, 1991).

Therefore, it seems relevant to in-depth research on coaches' knowledge of sport psychology, their perceptions about the importance of psychological preparation and their receptiveness to work with sport psychologists. However, to date, little research has been conducted under these research topics applied to disability sport coaches. Although literature about which are, and how to develop the psychological skills of athletes with disabilities is reasonably developed (Hanharan, 2007; Harlick \& McKenzie, 2000; J. J. Martin, 2005), studies about the contribution of the coach for the successful implementation of PST programs among athletes with disabilities are quite scant. In the same way, research has shown interest in understanding the characteristics of coaches who work with athletes with disabilities (Cregan, Bloom, \& Reid, 2007; DePauw \& Gravon, 1991), but little attention has been paid to the psychological intervention of the coaches.

We could only find one article where the purpose was to examine coaches' beliefs concerning the usefulness of sport psychology techniques in disability sport. Robbins and Dummer (2001) interviewed coaches of elite swimmers with disabilities and concluded that coaches were aware of the psychological factors that influenced their athletes such as anxiety, confidence, motivation and focus. The main concerns expressed by them were how to motivate the athletes, what the best techniques to reduce anxiety before competition are and how to deal with individual cohesion in a sport team. The coaches also raised several doubts, which demonstrated their interest and desire to learn more about sport psychology techniques. Despite that, they did not define the assistance to psychological preparation as a priority, and the majority did not develop PST programs. The main reasons for not making it a priority and therefore not developing PST programs, pointed to financial barriers, lack of time and the reluctance to allow outsiders to interfere with their work and coach plan. Nevertheless, Gorley, Lobling, Lewis, and Bruce (2002) indicated that, after developing a PST program with basketball players with intellectual disabilities, the evaluation of the program made by the coaches was positive. Coaches reported that the techniques that athletes learnt were useful for relaxing and thinking about the game they had to play. Athletes have become more able to overcome obstacles caused by injuries and external factors by using the psychological training. Coaches also pointed out that the implementation of consistent PST program would bring huge benefits during the games and it would be valuable to have a sport psychologist on the team.

Hanraham, Grove, and Lockwood (1990) recommended that someone with knowledge in sport psychology and with practical experience with athletes with disabilities should conduct the implementation of PST for athletes with visual impairment. The authors believe in the ability of the coach to develop such a type of training after consulting a sport psychologist, regarding the selection of the content and structure of the program. However, it was also stated that better results could be reached if a sport psychologist was responsible for conducting the PST program.

The success of the application of PST programs, in athletes with disabilities, requires a considerable level of knowledge, experience and comfort in the work with athletes with disabilities and sport psychology (Travis \& 
Sachs, 1991). Therefore, the contribution of the coach assumes an even greater importance because he or she is the person that better knows the athlete's sport psychological needs in the context of a specific sport and of a specific disability.

Therefore, there is a research gap on the beliefs, knowledge, and perceptions of disability sport coaches about sport psychology and, specifically, about psychological skills. Consequently, it is our aim to explore: 1) the educational background of disability sport coaches, 2) the perceptions of the coaches on the importance of psychological preparation for their athletes, and 3) the opinions of the coaches regarding the role of sport psychologists.

\section{Method}

\subsection{Participants}

A purposive sample of ten coaches ( 8 males; 2 females) included in the Portuguese Paralympic Project London 2012 composed this study. Elite coaches were selected in order to represent the four sports included in the Paralympic Project until June 2011 (swimming=4; track and field=2; boccia=3; rowing=1). Most of the coaches trained athletes with a physical disability and only one coached athletes with visual impairment. The coaches' ages ranged from 25 to 65 years $(\mathrm{M}=45.7 \mathrm{yrs}$.; $\mathrm{SD}=13.0 \mathrm{yrs}$.) and their experience as a coach of elite athletes with disabilities ranged from 2 to 22 years ( $\mathrm{M}=10.3 \mathrm{yrs}$.; $\mathrm{SD}=7.2 \mathrm{yrs}$.). All the participants coached athletes who had participated in major international competitions (e.g., Paralympic Games, World Cups, World and European Championships) and half of them were several times medaled in Paralympic Games. Three of the participants also played the role of national coaches. The commission encharged for the ethical issues approved this research. Coaches gave their informed consent to participate in the study.

\subsection{Instrument}

The data were collected from a semi-structured interview guide organized in three major phases. Phase 1 introduced coaches to the study's goals and to the interview's structure and content. This phase also aimed to establish rapport with the participants. Phase 2 composed the main body of the interviewed and separated it into the following sections: Section 1 examined the coaches' educational background on sport psychology by asking them specific questions (e.g., What kind of contact did you have with sport psychology knowledge? Do you apply that knowledge in your training and competition coaching routines?); Section 2 explored the importance assigned to psychological preparation (e.g., What is your opinion about the importance of psychological preparation in sport? Which psychological skills do you considered crucial for sports performance?); and Section 3 analysed the coaches' opinions on sport psychologists (e.g., What is your opinion about the importance of sport psychologists? Are you receptive to work with these experts?). Finally, phase 3 concluded the interview by recording demographic and sport data (e.g., age, gender, years of experience and major career results) and also explored the participant's perception of the interview process (e.g., style and content). Opportunity was also given to coaches to provide final comments regarding the interview topics.

The structure of the interview guide was based on Robbins and Dummer (2001) research, as well as recommendations from the qualitative literature. The last mentioned study was the only one found in disability sport context with a purpose similar to ours and also used interview method. The guide was pilot-tested with two goalball coaches, the national coach and his assistant coach (one male; one female) following which minor refinements to the guide were made.

\subsection{Protocol and Data Analysis}

All interviews were conducted face-to-face by the lead author between the months of January and October 2011. The interviewer was familiar with the background and context of the participants due to her previous experience as coach in the field of disability sport. The interviews were tape recorded, lasted an average off one hour and were transcribed verbatim. Afterwards, the transcribed interviews were sent to the coaches for content approval.

According to the suggestions of Patton (2002), we followed an inductive-deductive content analysis to analyse the data. This process involved the following phases: i) reading the material several times to deepen the main researcher's understanding of the content; ii) organizing raw data into meaningful themes and units that emerged from the participant's statements; and iii) finding common denominators and clustering the data into a content hierarchy induction of lower and higher themes (i.e., first and second-order subthemes) until it is no longer possible to generate a new level of thematic representation (i.e., general dimension).

In order to control individual bias and ensure verifiability of the findings, all the data were presented and discussed with another author to serve as a sort of "devil's advocate" (Marshall \& Rossman, 1995), and consequently necessary changes were made. Ultimately, the lead author read again the interview transcripts 
while comparing them and validating them against the first-, second-order and general dimension, ensuring that research questions were being answered.

\section{Results}

The inductive-deductive analysis exposed three general dimensions emerging from 63 raw data themes mentioned by the elite coaches. The dimensions were abstracted from 10 second-order subthemes and these from 15 first-order subthemes. The general dimensions are represented in figures 1-3. Frequency analysis and representative quotations from the transcripts are interspersed amid the results to clarify the emergent themes.

\subsection{Educational Background in Sport Psychology}

This dimension made evident the coaches' exposure to sport psychology and their applied knowledge in the field. Seventeen raw data themes comprised this dimension and three second-order subthemes were used to define it (figure 1).

\begin{tabular}{|c|c|c|c|}
\hline Raw Data Themes*1 & $\begin{array}{c}\text { First Order *2 } \\
\text { Subthemes }\end{array}$ & $\begin{array}{l}\text { Second Order } \\
\text { Subthemes }\end{array}$ & Dimensions \\
\hline $\begin{array}{l}\text { Physical Education Teachers } \\
(\mathrm{n}=6) \text {. } \\
\text { Master in Adapted Physical } \\
\text { Activity }(\mathrm{n}=2) \text {. } \\
\text { Contact with SP curricular unit } \\
(\mathrm{n}=6) \text {. }\end{array}$ & $\begin{array}{c}\text { Academic } \\
\text { Courses } \\
(n=6)\end{array}$ & & \\
\hline $\begin{array}{l}\text { Swimming course coach }(n=1) \text {. } \\
\text { Athletics course coach }(n=1) \text {. } \\
\text { SP international conference : SP } \\
\text { applied to Boccia" }(n=2) \text {. } \\
\text { Contact with SP contents }(n=4) \text {. } \\
\text { Boccia coaching courses training } \\
\text { need to include the psychological } \\
\text { preparation approach }(n=1) \text {. }\end{array}$ & $\begin{array}{c}\text { Coaching } \\
\text { Training } \\
\text { Courses } \\
(n=4)\end{array}$ & $\begin{array}{c}\text { Formal } \\
\text { Education }\end{array}$ & \\
\hline $\begin{array}{l}\text { Family }(n=1) \\
\text { Experience as former athlete } \\
(n=1) \text {. } \\
\text { Experience as coach }(n=3) \text {. } \\
\text { Previous contact with sport } \\
\text { psychologists in non-disability } \\
\text { sport }(n=1) \text {. }\end{array}$ & $\begin{array}{c}\text { Personal } \\
\text { Experiences } \\
(\mathrm{n}=5)\end{array}$ & $\begin{array}{c}\text { Personal } \\
\text { Experiences }\end{array}$ & $\begin{array}{l}\text { Educational } \\
\text { Background }\end{array}$ \\
\hline $\begin{array}{l}\text { Application of some } \\
\text { psychological techniques in } \\
\text { training and competition }(n=3) \text {. } \\
\text { Insufficient }(n=3) \text {. } \\
\text { Not scientific based intervention } \\
(n=2) \text {. } \\
\text { Out of my coaches' skills }(n=2) \text {. } \\
\text { Need to provide applied } \\
\text { knowledge and tool to the } \\
\text { coaches }(n=2) \text {. }\end{array}$ & $\begin{array}{l}\text { Self-Evaluation } \\
\text { of SP Knowledge } \\
\qquad(\mathrm{n}=10)\end{array}$ & $\begin{array}{l}\text { Self-Evaluation } \\
\text { of SP Knowledge }\end{array}$ & \\
\hline
\end{tabular}

Figure 1. Coaches' educational background in Sport Psychology (SP)

(Note $1 \& 2$ ) The formal education of coaches in sport psychology was based on academic courses $(\mathrm{n}=6)$ and coaching training courses $(\mathrm{n}=4)$. Six participants were Physical Education (PE) teachers and two of them held a master in Adapted Physical Activity (APA). All referred to having contact with sport psychology curricular units and others related with the psychological field (e.g., psychopedagogy and developmental psychology). Three coaches conducted their graduation thesis in the field of sport psychology during their courses. Three of the six $\mathrm{PE}$ teachers referred to additional knowledge in sport psychology due to the participation in coaching training 
courses. One coach also explained that his only formal psychological education was the hours of sport psychology within his swimming coaching courses.

However, five coaches explained that their knowledge in sport psychology resulted from their personal experiences, such as their own experience as athlete $(n=1)$ and coach $(n=3)$. The next comment expresses this perspective:

"My experience is only my work with the athletes...I don't have knowledge in sport psychology but I am 63 years old and have 22 years of competitive experience in rowing."

When the participants were asked to self- evaluate their knowledge in sport psychology, in order to promote psychological skills training, only three acknowledged applying some psychological techniques. Most of the coaches considered insufficient $(n=3)$ or not scientific based $(n=2)$ their applied knowledge in sport psychology. The following quotation is quite representative of that:

"I don't have the scientific tools to asses and apply protocols aiming to improve the performance of my athletes. There is a common sense, our intuition, that helps to detect problems but not on a scientific base."

\subsection{Importance of Psychological Preparation}

Twenty-four raw data themes were included in this dimension, which is related to the coaches' perspectives about the importance of psychological preparation and the psychological skills they elected as crucial for sport performance. The dimension was comprised of two second-order subthemes: importance of psychological preparation and crucial psychological skills in sport, which were both defined by three first-order subthemes (figure 2).

\begin{tabular}{|c|c|c|c|}
\hline Raw Data Themes*1 & $\begin{array}{c}\text { First Order *2 } \\
\text { Subthemes }\end{array}$ & $\begin{array}{l}\text { Second Order } \\
\text { Subthemes }\end{array}$ & Dimensions \\
\hline $\begin{array}{l}\text { Mental training is one of the } \\
\text { factors of the elite training }(\mathrm{n}=4) \text {. } \\
\text { It has to be integrated in the } \\
\text { training }(\mathrm{n}=1) \text {. } \\
\text { Excellent fit not enough when the } \\
\text { mind fails }(\mathrm{n}=2) \text {. }\end{array}$ & $\begin{array}{c}\text { One of the } \\
\text { Performance } \\
\text { Components } \\
\quad(\mathrm{n}=5)\end{array}$ & & \\
\hline $\begin{array}{l}\text { A "strong mind" will have better } \\
\text { results ( } \mathrm{n}=2) \text {. } \\
\text { In high-level competition the mind } \\
\text { is the last frontier }(\mathrm{n}=3) \text {. } \\
\text { To stay at the top, the athlete } \\
\text { needs psychological support } \\
(\mathrm{n}=2) \text {. }\end{array}$ & $\begin{array}{c}\text { Crucial in } \\
\text { Elite Sport } \\
\quad(\mathrm{n}=7)\end{array}$ & $\begin{array}{l}\text { Importance } \\
\text { of } P P\end{array}$ & \\
\hline $\begin{array}{l}\text { The performance of boccia } \\
\text { athletes is dependent on the } \\
\text { psychological influence of the } \\
\text { companion (e.g., personal coach, } \\
\text { sport assistant) }(\mathrm{n}=2) \text {. } \\
\text { Boccia athletes need autonomy } \\
\text { and independence to act by } \\
\text { themselves }(\mathrm{n}=1) \text {. }\end{array}$ & $\begin{array}{c}\text { Specific Disability } \\
\text { Issues } \\
(\mathrm{n}=2)\end{array}$ & & $\begin{array}{l}\text { Psychological } \\
\text { Preparation } \\
\text { (PP) }\end{array}$ \\
\hline $\begin{array}{l}\text { Determination }(\mathrm{n}=2) \text {. } \\
\text { Concentration }(\mathrm{n}=4) \text {. } \\
\text { Stress management }(\mathrm{n}=5) \text {. } \\
\text { Activation }(\mathrm{n}=1) \text {. } \\
\text { Emotional control }(\mathrm{n}=4) \text {. } \\
\text { Self-confidence }(\mathrm{n}=1) \text {. } \\
\text { Motivation }(\mathrm{n}=1) \text {. }\end{array}$ & $\begin{array}{l}\text { Psychological } \\
\text { Skills } \\
(\mathrm{n}=10)\end{array}$ & & \\
\hline $\begin{array}{l}\text { Imagery }(\mathrm{n}=2) \\
\text { Goal-setting }(\mathrm{n}=2)\end{array}$ & $\begin{array}{c}\text { Psychological } \\
\text { Techniques } \\
(\mathrm{n}=3)\end{array}$ & $\begin{array}{c}\text { Crucial } \\
\text { Psychological } \\
\text { Skills in Sport }\end{array}$ & \\
\hline $\begin{array}{l}\text { Wilfulness }(\mathrm{n}=1) \text {. } \\
\text { Honesty }(\mathrm{n}=1) \text {. } \\
\text { Spirit of sacrifice }(\mathrm{n}=2) \text {. } \\
\text { Arrogance }(\mathrm{n}=1) \text {. } \\
\text { Manage the failure }(\mathrm{n}=1) \text {. } \\
\text { Autonomy in decision making } \\
(\mathrm{n}=1) \text {. } \\
\text { Focus in success }(\mathrm{n}=1) \text {. }\end{array}$ & $\begin{array}{c}\text { Other } \\
\text { Psychological } \\
\text { Attributes } \\
(\mathrm{n}=4)\end{array}$ & & \\
\hline
\end{tabular}

Figure 2. Coaches' perceptions about the importance of Psychological Preparation (PP) 
The first second-order subtheme, importance of psychological preparation, enumerated the several reasons why coaches considered psychological preparation important for sport performance. All the participants were unanimous in recognizing the important role of psychological preparation, specifically as one of the sport performance components $(\mathrm{n}=5)$ and as crucial in elite level sport $(\mathrm{n}=7)$.

"In high level competition, the mind is the last barrier to achieve. That is why so many athletes with great physical, technical and technical skills don't reach there."

"Nowadays, to win or to lose a competition is decided psychologically."

Two boccia coaches raised different perspectives regarding the psychological preparation of boccia athletes. Both coaches considered that the psychological preparation of the athletes was highly influenced by the psychological skills of their coaches and sports assistants. Therefore, particular attention should be given to those sport practioners. Moreover, when approaching the psychological preparation of boccia athletes, autonomy and independence should be highlighted. The coach identified it as one of the big gaps in psychological preparation of Portuguese boccia athletes:

"For many years, we did not care about the psychological side of the athlete. We were too worried about the technical and technical aspects of the game and neglected the psychological issues. Now, we understand that something has to change, we cannot overprotect the athletes, acting and thinking for them. ... That was a mistake."

The second second-order subtheme, crucial psychological skills in sport, stressed the importance given by the whole sample to psychological skills such as concentration $(n=4)$, stress management $(n=5)$ and emotional control $(n=4)$. However, only three coaches mentioned the importance of psychological techniques, namely imagery and goal-setting. Some coaches also mentioned a range of other psychological attributes (e.g., spirit of sacrifice, arrogance, and focus in success).

\subsection{Perceptions about Sport Psychologists}

This dimension included 22 raw data themes that were emerged directly into five second-order subthemes: importance of sport psychologists, previous experience with sport psychologists, receptiveness to work with sport psychologists, type of collaboration coach-sport psychologists and barriers to sport psychologists' intervention (figure 3).

All coaches were unanimous in stating the important role of sport psychologists and several reasons were presented to justify that position. Two coaches gave equal importance to sport psychologists as to other sport sciences specialists (e.g., coach, physiotherapist and nutritionist) that can help athletes reach their full potential. The preventive role that sport psychologists may have to avoid the appearance of psychological problems was also mentioned. One of the participants said:

"More important than solving the problems, the sport psychologist is important to prevent the appearance of problems in order to boost sport results."

Some coaches $(n=4)$ gave examples of other countries that have sport psychologists included in the national teams. Their international experiences and observations made them realize that most of the national teams worldwide have access to this service. For instance, one coach said:

"I have spoken with many coaches, colleagues from other countries, and all of them have sport psychologists supporting them in the clubs and national teams. ... Portugal has failed in this."

Regarding the previous experience with sport psychologists, only one swimming coach was currently working with a sport psychologist. The coach explained that each season he had access to a sport psychologist in training who supported his athletes. However, the coach also considered this support inadequate because the sport psychologists were inexperienced and changed each year. Therefore, it was not possible to develop a systematic work. Although working with a general psychologist, one boccia coach considered that support responsible for the great results that his athletes had been accomplishing.

When the participants were asked about their receptiveness to work with sport psychologists, full agreement was noticed and the coaches even suggested specific types of coach-sport psychologist collaboration. Three coaches focused on the importance of sport psychologist to act over them, providing psychological support to the coach himself. Other participants highlighted the need to have a sport psychologist in the club $(n=1)$ or a punctual intervention of the sport psychology in the most important moments of the season (e.g., pre-competition).

Finally, coaches also identified barriers to sport psychologists' intervention. The most highlighted were as follows: i) the financial costs; ii) lack of time; iii) lack of coach awareness for the importance of psychological 
support in sport; and iv) lack of receptiveness of the athletes to engage in psychological training. Two coaches considered important to have sport psychologists with specific knowledge about the sport and its skills.

\begin{tabular}{|c|c|c|c|}
\hline Raw Data Themes*1 & $\begin{array}{c}\text { First Order *2 } \\
\text { Subthemes }\end{array}$ & $\begin{array}{l}\text { Second Order } \\
\text { Subthemes }\end{array}$ & Dimensions \\
\hline $\begin{array}{l}\text { Equal importance others sport } \\
\text { sciences specialists }(\mathrm{n}=3) \text {. } \\
\text { Preventive perspective }(\mathrm{n}=3) \\
\text { International examples }(\mathrm{n}=4)\end{array}$ & $\begin{array}{l}\text { Importance } \\
\text { of SPs } \\
\quad(\mathrm{n}=10)\end{array}$ & $\begin{array}{l}\text { Importance } \\
\text { of SPs }\end{array}$ & \\
\hline $\begin{array}{l}\text { Never }(\mathrm{n}=7) \text {. } \\
\text { As former athlete }(\mathrm{n}=1) \text {. } \\
\text { Currently working with a SP in } \\
\text { training }(\mathrm{n}=1) \text {. } \\
\text { Currently working with general } \\
\text { psychologist }(\mathrm{n}=1) \text {. }\end{array}$ & $\begin{array}{l}\text { Previous } \\
\text { Experience } \\
\text { with SPs } \\
(\mathrm{n}=10)\end{array}$ & $\begin{array}{c}\text { Previous } \\
\text { Experience } \\
\text { with SPs }\end{array}$ & \\
\hline $\begin{array}{l}\text { Full receptiveness }(n=10) \text {. } \\
\text { Coaches, athletes and sport } \\
\text { assistants are eager to work with } \\
\text { SPs }(n=1) \text {. }\end{array}$ & $\begin{array}{l}\text { Receptiveness to } \\
\text { Working with SPs } \\
\quad(\mathrm{n}=10)\end{array}$ & $\begin{array}{l}\text { Receptiveness to } \\
\text { Working with } \\
\text { SPs }\end{array}$ & \\
\hline $\begin{array}{l}\text { To act over the athlete }(n=3) \text {. } \\
\text { To act over the coach }(n=3) \text {. } \\
\text { To support the coach }(n=1) \text {. } \\
\text { Systematic work }(n=1) \text {. } \\
\text { Favourable to have a SPs in the } \\
\text { club }(n=1) \text {. } \\
\text { To work in the most important } \\
\text { moments of the sports season } \\
(n=1) \text {. }\end{array}$ & $\begin{array}{c}\text { Type of } \\
\text { Collaboration } \\
\text { Coach-SPs } \\
(\mathrm{n}=10)\end{array}$ & $\begin{array}{c}\text { Type of } \\
\text { Collaboration } \\
\text { Coach-SPs }\end{array}$ & $\begin{array}{c}\text { Sport } \\
\text { Psychologists } \\
\text { (SPs) }\end{array}$ \\
\hline $\begin{array}{l}\text { Lack of coach awareness }(\mathrm{n}=2) \text {. } \\
\text { Lack of athlete receptiveness } \\
(\mathrm{n}=2) \text {. } \\
\text { Lack of access to the } \\
\text { knowledge/service }(\mathrm{n}=1) \text {. } \\
\text { Lack of time }(\mathrm{n}=2) \text {. } \\
\text { Geographical barrier }(\mathrm{n}=1) \text {. } \\
\text { Financial barrier }(\mathrm{n}=4) \text {. } \\
\text { Lack of sport specific knowledge } \\
(\mathrm{n}=2) \text {. }\end{array}$ & $\begin{array}{l}\text { Barriers to SPs } \\
\text { Intervention } \\
\quad(n=6)\end{array}$ & $\begin{array}{l}\text { Barriers to SPs } \\
\text { Intervention }\end{array}$ & \\
\hline
\end{tabular}

Figure 3. Coaches' perceptions about Sport Psychologists (SPs)

\section{Discussion}

The purpose of this exploratory study was to examine the educational background of disability sport coaches, the perceptions of the coaches on the importance of psychological preparation for their athletes, and the opinions of the coaches regarding the role of sport psychologists.

Regarding the formal education in sport psychology, about half of the coaches had contact to sport psychology curricular units in their academic courses. Six participants presented a university degree in the field of Physical Education and Sport, with two of them being masters in APA, and three conducted their thesis in the sport psychology field. Therefore, this group of coaches exhibited an education background in the field of sports sciences and previous contact with in sport psychology. These results seem to contrast with the statement of Martin and Wheeler (2011) about the lack of coaches with sport science education in disability sport. However, it is important to note that our sample included only elite coaches with experience in major sport events such as Paralympic Games and the World and European championships. In addition, some high-level athletes, from wealthy countries, have had increasing access to high level coaching, in similar patterns to athletes without disabilities (Martin \& Wheeler, 2011). Therefore, more research is needed to examine the educational level of Portuguese coaches in other levels of competition (i.e., national). 
One of the boccia coaches stressed the importance of including specific educational content in psychological preparation in the coaching courses because it is non-existent. Likewise, Samulski, Noce and Costa (2011) suggested that coaches' education programs should include psychological topics such as philosophy of coaching, motivation, leadership and communication skills. Our results seem to show that organizational structures of disability sport in Portugal, responsible for the training and education of coaches, does not always include sport psychology and psychological skills contents in their courses.

Moreover, one of the boccia coaches also called attention to the lack of academic qualifications of most of the elite boccia coaches and highlighted the practical experience as a major source of knowledge in sport psychology. Half of the sample considered that their knowledge came from personal experiences, especially coaching experience. Similarly, Gould et al. (1999) suggests that the coaching experience and the daily work with the athletes play an important role in the coaches' knowledge in sport psychology.

When the coaches self-evaluate their knowledge in sport psychology, only three participants considered themselves able to teach psychological skills. Several coaches considered their knowledge insufficient because it was too generalist, too theoretical and did not provide the practical tools needed to an applied intervention. Two coaches even mentioned that sport psychology intervention was completely out of their coaching abilities. These findings are in line with the study conducted by Robbins and Dummer (2001) about the use of sport psychology by swimming coaches of athletes with disabilities. The authors stated that most of the coaches presented a limited, weak or inconsistent use of sport psychology techniques. Likewise, Sullivan and Hodge (1991) assessed the perceptions on sport psychology of 46 national coaches and found that $73 \%$ of the sample considered their knowledge in sport psychology unsuitable. A group of tennis coaches studied by Gould et al. (1999) presented several recommendations regarding the type of psychological skills education for the coaches. The participants highlighted the need of more user-friendly information focusing on concrete examples and activities, having more resources (e.g., audio and video formats) available and involving coaches in the process of learning how to teach psychological skills. Therefore, efforts should be made in order to allow the access of Portuguese disability coaches to a diversity of sport psychology resources such as sport psychology textbooks, articles, videos and audiotapes, conferences/presentations and educational workshops.

Consequently, provisions should be made to invest in the education of Portuguese coaches in order to increase the opportunities to receive sport psychology knowledge, and specifically provide adequate training in psychological skills and techniques. Research showed that coaches with more certification pointed out the importance of analysing and detecting the athlete' psychological skills and felt they needed to practice psychological skills themselves in order to become able and confident in teaching them (Gould et al., 1999). Moreover, research shows that coaching education efforts are positively associated with the use and success of PST strategies (Gould, Hodge, Peterson, \& Petlichkoff, 1987). Therefore, coaches' applied knowledge in sport psychology is important to initiate and maintain quality psychological training for their athletes. As suggested by Sullivan and Hodge (1991), coaches need to have knowledge about the existence of the different psychological training strategies available for use with different athletes, in different situations and at different times.

All participants showed a favourable and positive perspective over the importance of psychological preparation, what was also found in several studies (Gould et al., 1999; Partington \& Orlick, 1987; Sullivan \& Hodge, 1991), and different reasons emerged from their statements. Half of the sample pointed out the importance of psychological preparation as one of the performance components. This perspective is quite valuable because literature showed some coaches' erroneous interpretation of psychological training as a "quick fix" or a miraculous formula for performance success (Burton \& Raedake, 2008; Weinberg and Gould, 2011). Time and effort has to be dedicated to the training of psychological skills and psychological preparation must be seen as one of the components of the coaching methodology. Gould et al. (2009) stated that psychological preparation is not the only critical factor that determines sport performance. Rather, psychological preparation has to be seen in a broader perspective, according to social and motivational environment where the athlete exists.

Two coaches raised a specific disability issue concerning boccia players. These participants highlighted that attention should be given to the psychological skills of sport assistants because their psychological preparation may influence the players' performance. These findings are in line with Badwen (2006) who highlighted the need of collaborative psychological work between athletes and their supportive practioners such as guide athletes (e.g., track and field for athletes with visual impairment) or sport assistants (e.g., boccia players). In this context, it is important to say that many athletes with disabilities have to rely on the "other people" (J. J. Martin, 1999) to be able to accomplish their training and daily-life activities. This dependency on the "other" may be related with sports practice itself (e.g., boccia sport assistant or athlete guide) or with the unique challenges that athletes with disabilities have to face such as transportation difficulties (J. J. Martin, 1999), lack of accessibility to buildings, 
parking and sport venues (Hanrahan, 1995). In athletes with severe disabilities this need from support from "other people" can be associated with the fulfilment of basic life skills such as communication or hygiene care. Thus, the level on dependency from "other people," provides a close and systematic contact between the athlete and the personal assistant. In this context, the coach has also to dedicate time to the psychological preparation of the "other people," who are in close connection with the athlete because their psychological influence over the athlete can be determinant.

The coaches' appraisal of the most crucial psychological skills in sport pointed toward a dominance for stress management, concentration and emotional control. Similarly, these skills were also highlighted by New Zealand coaches when asked to rate the importance of psychological skills (Sullivan \& Hodge, 1991). Concentration and emotional control were also important psychological skills pointed out by junior tennis coaches (Gould et al., 1999), but stress management was not mentioned by them. This may be related to the difference of ages and level of competition of the athletes trained by the surveyed coaches when compared to our sample. Gould et al. (1999) examined the importance placed on psychological skills by tennis coaches who worked with athletes ranging in age from 12 or under to 16 years. Possibly, in this age group athletes do not have to face demanding competition situations that may require stress management skills. For example, elite swimming coaches of athletes with physical disabilities also highlighted focus and anxiety as common issues for all the athletes, with and without disabilities (Robbins \& Dummer, 2001).

Our findings seem to put in evidence a high status of sport psychology and psychological preparation among Portuguese elite coaches working with athletes with disabilities. Coaches were aware of the importance of psychological preparation for a successful sport performance and elected a range of crucial psychological skills and attributes in sport. Therefore, an important first step seems to be accomplished regarding the recognition of sport psychology as an integrative sport sciences unit in the coaching methodology. This assumed awareness about the importance of sport psychology is crucial to increase the opportunities of collaboration between coaches and sport psychologists. Consequently, it was not surprising the full agreement of the sample about the importance of sport psychologists.

In relation to previous experience with sport psychologists, only one coach had the support of a sport psychologist but that coach considered the service inappropriate because it was conducted by a sport psychologist in training, without experience, that changed in each sport season. This almost non-existent availability of sport psychologist services for coaches seems to be more related with disability sport, because research in non-disability sport field showed that elite coaches have some kind of previous experience with sport psychologists during their careers (Gould, Tammen, Murphy, \& May, 1991; Johnson, Andersson, \& Fallby, 2011; Partington \& Orlick, 1987).

The participants also exhibited full receptiveness to work with sport psychologists. In a wide range study with 117 participants (coaches, athletes and administrators), sport psychologists were also rated positively on a diverse set of skills (Gould et al., 1991). In the same way, Sullivan and Hodge (1991) surveyed coaches about sport psychology and found that most of the participants agree to work with a sport psychologist.

The emergent theme, type of coach-sport psychologist collaboration, put in evidence the coaches' suggestions of the development of a cooperative relationship between both experts. One swimming coach defended that sport psychologists should be hired to be in her club providing permanent psychological support while one boccia coach argued that, due to financial constraints, sport psychologists should intervene in the most important moments of the sport season. Despite the different forms of support that can be established, according to the specific conditions of each club or team, the straight collaboration between coach and sport psychologist is critical for its success. The coach-sport psychologist relationship must be developed in terms of mutual support, clear communication of plans and aims and respect of the boundaries of each role (Morris, 1997). Another theme raised was the importance of sport psychologists to act over the coaches. Some participants considered that sport psychologists were useful to advise the coaches about their behaviour and attitudes over the athletes. Additionally, problems related with the ability of the coaches to deal with their own stress and anxiety in competition was expressed. This twofold perspective was well described by Anderson (2009). One form of coach consultation is focused on the coaching practices. The coach is the primary client and seeks information to support the psychological preparation of the athletes. Another situation occurs when coaches seek consultation not for their athletes but for their own personal and professional needs (e.g., anxiety) (Anderson, 2009). Samulski et al. (2011) stated that it is important that sport psychologists know how to support and counsel coaches and athletes at the same time. The authors explained that during Athens 2004 Olympic Games, Brazilian national coaches demonstrated problems related to leadership, team building, motivation and communication. 
Consequently, the Brazilian Paralympic Committee was advised to promote coaches' education programs in order to develop psychological and social skills.

As previously mentioned, favourable attitudes towards sport psychologists and receptiveness to work with them were exhibited by our sample. However, in Portuguese disability sport, it is clear that sport psychology services for coaches are not developed and are quite inaccessible. Consequently, the need to raise awareness of administrators and managers in national teams, clubs and national sports federations for the important role of sport psychologists to empower coaches and athletes in the achievement of higher results urges. They have the means and the power to hire sport sciences specialists to support the coaches' work in the practice and competition setting.

Nevertheless, some participants expressed a group of barriers that limited, in the participant's view, a sport psychologist's intervention. The reasons for that are also well described in literature such as financial barriers, lack of time or lack of athlete's receptiveness (Burton \& Raedake, 2008; Gould et al., 1999; Johnson et al., 2011; Robins \& Dummer, 2001). Regarding the first-abovementioned barrier, it is important to note that serious financial problems are affecting Portuguese disability sport structures nowadays. As far as we are aware, the beginning of national championships, in several sports, has been delayed due to the lack of budget of the clubs to support the costs inherent to the participation in competition events. Similarly, several elite athletes have seen their international participations reduced to the minimal due to the lack of financial support. In a context like this, why financial investment in sport psychology services is not a priority is understandable. Portuguese disability sport always faced poor financial conditions when compared with non-disability sport, but nowadays the worldwide crises have severely affected these organizations.

The coach can be a powerful inhibitor for the entry of sport psychologists in the teams. Lack of coaches' awareness related to the lack of knowledge in sport psychology or with the perception that sport psychologists fail to clarify their services were the major barriers identified by Johnson et al. (2011). The coaches interviewed by Robins and Dummer (2001) also stated their lack of interest or willingness to work with sport psychologist. In this context, it is pertinent to add to the discussion the sport psychologists' perspectives, regarding Olympic sport psychologists' best-ever consulting experience (Partington \& Orlick, 1991). The research showed that best-ever consulting occurred when athletes and coaches were committed and receptive to what the consultant had to offer and when the consultant had a considerable amount of time to work with both coaches and athletes on an individual basis in training and competition settings.

Two coaches argued that for good practice sport psychologists would need to have in-depth knowledge in the sport at hand. One of them even explained that sport psychologists should have an athletic background on the sport. Regarding the consultant styles and approaches, Partington and Orlick (1987) also stated that coaches valued consultants who showed interest in and readiness to learn about their sport. Similarly, Gould et al. (1991) found that coaches from the Olympic level suggested that sport psychologists should improve their sport-specific knowledge.

Interestingly, literature also mentioned other barriers that were not presented in our study, for example, the personality of the consultants. Some coaches appreciated the importance of an interested, caring, and down-to-earth person who respects the others (Johnson et al., 2011). Integration of the sport psychologists with the players and coaching staff was another problem raised in several studies (Johnson et al., 2011; Robbins \& Dummer, 2001; Sullivan \& Hodge, 1991). Possibly, the interviewed coaches of our sample did not mention personal characteristics of the sport psychologists because their previous experience with these experts is quite scant. Therefore, during their coaches' career they never, in some way, faced problems related with the integration of sport psychologists in their technical staff. In this context, it is pertinent to enunciate some characteristics of excellent counselling namely, genuineness, confidence, respect, empathy, positive attitude, positive emotional support, social perception, effective listening and communication (Henschen, 2005). However, in the field of disability sport additional attributes are required including: i) specific knowledge on the type and degree of the disability because it may require some adaptations on the psychological techniques (Hanrahan et al., 1990; Travis \& Sachs, 1991); ii) open-mind, flexibility and creativity to adapt methods and instruments to assess psychological skills (Hanrahan, 1998); and iii) avoid negative attitudes of protectionism or prejudice about the abilities of the athletes to improve their psychological skills (Gorley, et al., 2002; Hanrahan, 1998).

\section{Conclusion}

Although most of the coaches exhibited an educational background in sport sciences and in sport psychology, they did not feel able to apply it on regular basis. Only a small number of coaches acknowledged an effective intervention in psychological skills training. Our results reflected a high status of sport psychology among 
leading coaches in Portuguese disability sport. The coaches were unanimous in acknowledging the importance of psychological preparation, of the training of psychological, and of the role of sport psychologists. The participants showed full receptiveness to work with sport psychologists and highlighted the need to be supported by these experts. Therefore, further research should actively promote the implementation of PST programs in Portuguese disability sport, supported and guided by sport psychologists.

A specific disability issue regarding the importance of sport assistants in the psychological preparation of the athletes emerged in our study. More research should be developed in order to identify the psychological skills of these specific practitioners and to clarify in which measure they influence the athlete's sport outcomes.

\section{Acknowledgements}

This research was funded by the Portuguese Foundation for Science and Technology (FCT).

\section{References}

Anderson, M. (2009). Sport psychology in practice. In B. W. Brewer (Ed.), Handbook of Sports Medicine and Science: Sport Psychology (pp. 121-132). Oxford, United Kingdom: Wiley-Blackwell Publishing.

Badwen, M. (2006). Providing Sport Psychology support for athletes with disabilities. In J. Dosil (Ed.), The Sport Psychologist's Handbook: A Guide for Sport-Specific Performance Enhancement (pp. 665-683). Chichester, United Kingdom: John Wiley and Sons, Inc. http://dx.doi.org/10.1002/9780470713174.ch29

Burton, D., \& Raedeke, T. D. (2008). Sport Psychology for Coaches. Champaign Illinois: Human Kinetics.

Caruso, A. (2004). Sport Psychology Basics. Spring City: Reedswain Publishing.

Cregan, K., Bloom, G., \& Reid, G. (2007). Career evolution and knowledge of elite coaches of swimmers with a physical disability. Research Quarterly for Exercise \& Sport, 78(4), 339-350.

DePauw, K. P., \& Gavron, S. J. (1991). Coaches of athletes with disabilities. Physical Educator, 48, 33-40.

Gorley, T., Lobling, A., Lewis, K., \& Bruce, D. (2002). An evaluative case study of a psychological skills training program for athletes with intellectual disabilities. Adapted Physical Activity Quarterly, 19(3), 350-363.

Gould, D., Flett, M. R., \& Bean, E. (2009). Mental preparation for training and competition. In B. W. Brewer (Ed.), Handbook of Sports Medicine and Science: Sport Psychology (pp. 53-63). Wiley-Blackwell Publishing.

Gould, D., Hodge, K., Peterson, K., \& Petlichkoff, L. (1987). Psychological foundations of coaching: Similarities and differences among intercollegiate wrestling coaches. The Sport Psychologist, 1(4), 293-308.

Gould, D., Medbery, R., Damarjian, N., \& Lauer, L. (1999). A survey of mental skills training knowledge, opinions, and practices of junior tennis coaches. Journal of Applied Sport Psychology, 11(1), 28-50. http://dx.doi.org/10.1080/10413209908402949

Gould, D., Tammen, V., Murphy, S., \& May, J. (1991). An evaluation of US Olympic sport psychology consultant effectiveness. The Sport Psychologist, 5(2), 111-127.

Hanrahan, S. J. (1995). Psychological skills training for competitive wheelchair and amputee athletes. Australian psychologist, 30(2), 96-101. http://dx.doi.org/10.1080/00050069508258911

Hanrahan, S. J. (1998). Practical considerations for working with athletes with disabilities. The Sport Psychologist, 12(3), 143-155.

Hanrahan, S. J. (2007). Athletes with disabilities. In G. Tenenbaum, \& R. C. Eklund (Eds.), Handbook of Sport Psychology (3rd ed., pp. 845-858). New Jersey, United States of America: John Wiley and Sons, Inc.

Hanrahan, S. J., Grove, J. R., \& Lockwood, R. J. (1990). Psychological Skills Training for the Blind Athlete: A Pilot Program. Adapted Physical Activity Quarterly, 7(2), 143-155.

Harlick, M., \& McKenzie, A. (2000). Psychological skills training for athletes with disabilities: A review. New Zealand Journal of Sports Medicine, 28(3), 64-66.

Henschen, K. (2005). Mental practice - skill orientated. In D. Hackfort, J. Duda, \& R. Lidor (Eds.), Handbook of Research in Applied Sport and Exercise Psychology: International Perspectives (pp. 19-36). Morgantown, Michigan: Fitness information Tecnhnology. 
Johnson, U., Andersson, K., \& Fallby, J. (2011). Sport psychology consulting among Swedish premier soccer coaches. International Journal of Sport and Exercise Psychology, 9(4), 308-322. http://dx.doi.org/10.1080/1612197X.2011.623455

Leffingwell, T. R., Durand-Bush, N., Wurzberger, D., \& Cada, P. (2005). Psychological Assessment. In J. Taylor, \& G. Wilson (Eds.), Applying Sport Psychology: Four Perspectives (pp. 85-100). Champaign Illinois, United States of America: Human Kinetics.

Marshall, C., \& Rossman, G. B. (1995). Designing qualitative research (2nd ed.). Thousand Oaks, CA: Sage.

Martin, J. J. (1999). A personal development model of sport psychology for athletes with disabilities. Journal of Applied Sport Psychology, 11(2), 181-193. http://dx.doi.org/10.1080/10413209908404199

Martin, J. J. (2005). Sport psychology consulting with athletes with disabilities. Sport and Exercise Psychology Review, 1(2), 32-39.

Martin, J. J., \& Wheeler, G. (2011). Psychology. In Y. C. Vanlandewijck, \& W. R. Thompson (Eds.), The Paralympic athlete: Handbook of sports medicine and science (pp. 116-134). Oxford, United Kingdom: Wiley-Blackwell.

Martin, S. B. (2005). High school and college athletes' attitudes towards sport psychology consulting. Journal of Applied Sport Psychology, 17(2), 127-139. http://dx.doi.org/10.1080/10413200590932434

Morris, T. (1997). Psychological skills training in sport: An overview (2nd ed.). Leeds: The National Coaching Foundation - BASES.

Partington, J., \& Orlick, T. (1987). The sport psychology consultant: Olympic coaches' views. The Sport Psychologist, 1(2), 95-102.

Partington, J., \& Orlick, T. (1991). An analysis of Olympic sport psychology consultants' best-ever consulting experiences. The Sport Psychologist, 5(2), 183-193.

Patton, M. (2002). Qualitative research \& evaluation methods (3rd ed.). Thousand Oaks: Sage Publications.

Ravizza, K. (1988). Gaining entry with athletic personnel for season long consulting. The Sport Psychologist, 2(3), 243-254.

Robbins, J. E., \& Dummer, G. M. (2001). Using Sport Psychology with Athletes with a Disability: A Call for Coach Education. Disability Sport Web Site. Retrieved March 17, 2009, from http://edweb6.educ.msu.edu/kin866/Research/resrobbins1.htm

Samulski, D. M., Noce, F., \& Costa, V. T. (2011). Mental preparation. In Y. C. Vanlandewijck, \& W. R. Thompson (Eds.), The Paralympic athlete: handbook of sports medicine and science (pp. 198-213). Oxford, United Kingdom: Wiley-Blackwell.

Sullivan, J., \& Hodge, K. P. (1991). A survey of coaches and athletes about sport psychology in New Zealand. The Sport Psychologist, 5(2), 140-151.

Travis, C. A., \& Sachs, M. L. (1991). Applied sport psychology and persons with mental retardation. The Sport Psychologist, 5(4), 382-391.

Voight, M., \& Callaghan, J. (2001). The use of sport psychology services at NCAA division I universities from 1998-1999. The Sport Psychologist, 15(1), 91-102.

Weinberg, R., \& Gould, D. (2011). Foundations of Sport and Exercise Psychology (5th ed.). Champaign Illinois: Human Kinetics.

\section{Notes}

Note 1. The number following each raw data theme indicates the number of times that it was reported.

Note 2. The number below the first order subthemes indicates the number of coaches who reported them.

\section{Copyrights}

Copyright for this article is retained by the author(s), with first publication rights granted to the journal.

This is an open-access article distributed under the terms and conditions of the Creative Commons Attribution license (http://creativecommons.org/licenses/by/3.0/). 